\title{
11th Congress of the European Association of Clinical Anatomy (EACA) held jointly with Summer Meeting of the British Association of Clinical Anatomists (BACA)
}

\author{
29th and 30th June and 1st July 2011 at the University of Padova, Italy
}

\author{
R. De Caro
}

(C) Springer-Verlag 2011

Dear Colleagues,

We are happy to announce that the 11th Congress of the European Association of Clinical Anatomy (EACA) will be held jointly with the Summer Meeting of the British Association of Clinical Anatomists (BACA) in Padova from 29 June to 1 July 2011.

It will certainly be a great cultural and scientific event and a further opportunity to discuss issues of mutual interest with many colleagues from across Europe.

The main topics will be clinical anatomy, neuroanatomy and embryology. As usual, a large part of the meeting will provide opportunities for delegates to update colleagues of developments in all the traditional topics of clinical anatomy and of the technological innovations that are more relevant for anatomy education. All sessions will be interactive and participants will be involved in the discussion.

The University of Padova is one of the oldest Universities in Europe, founded in 1222. The "motto" of the University of Padova rightly became Universa Universis Patavina Libertas (i.e. "Paduan liberty is universal and for all"). The most famous anatomists of the School in Padova were Andreas Vesalius, Realdus Colombus, Gabriel Falloppius, and William Harvey. The famous Anatomical Theatre, built by Hieronymous Fabricius Ab Acquapendente, is the oldest in the world (1594).

The opening ceremony will be at the Bo Palace, Ancient University Building, and will be followed by the traditional
Welcome Reception. Then, the meeting will be organized in parallel sessions at the Department of Anatomy. On Saturday, a workshop session will combine top presenters from all the Europe with invited lectures and practical dissection activities.

The beauties and the glamour of the city of Padova, with its monuments and museums, its culture and charms, will give you the possibility to easily move around, walking in its present and past. After the scientific sessions, you will be attracted by the Botanic Garden, the world's first botanical garden (1545) and world heritage of the UNESCO, the wonderful architecture of S. Anthony Basilica (1320), Palazzo della Ragione (1218), or to admire the beautiful paintings by Giotto at the Scrovegni's Chapel, one of the greatest monuments of figurative art of all time (1303-1305).

All the congress activities will be in the centre of the town or near the University Hospital, which is in walking distance from the major hotels.

Finally, you can have the opportunity to visit the area around Padova and the other towns, all rich in history and art (Venezia, Verona, Vicenza, Treviso, Bassano del Grappa, etc).

All details will be available at the following web site http://www.sabiwork.it/padova2011.

Arrivederci a Padova!
R. De Caro ( $\square)$

Department of Human Anatomy and Physiology,

University of Padova, Via A. Gabelli 65,

35121 Padua, Italy

e-mail: rdecaro@unipd.it 